\title{
Da suspeição à suspensão 0 enfraquecimento do sujeito no contexto da cena teatral contemporânea
}

\author{
Arthur E. A. Belloni
}

Cabe lembrar, ainda, no caso do teatro performativo brasileiro, as montagens do Grupo Sonda (liderado por Maria Esther Stockler e Jose

Agrippino de Paula) Tarzan $11{ }^{\circ}$ Mundo - 0 Mustang hibernado (1968) e Rito do amo selvagem (1969), nas quais circulavam figuras

emblemáticas como

Batman, Robin, Eva, Adão, o Papa, Mussolini, Marlon Brando, Papai Noel, Hitler,

Eva Braun, etc.

Arthur E. A. Belloni é doutorado em Artes Cénicas pela

Universidade de São Paulo (USP),

investigador do Grupo

de Investigação do

Desempenho

Espetacular (GIDE), do Departamento de Artes

Cénicas da mesma

instituição. Tem

desempenhado

actividade docente em várias universidades brasileiras, e é também

\section{Memória e imaginação}

Passado e futuro, memória e antecipação, o teatro, como afirma Lehmann no seu estudo sobre o pós-dramático, pode configurar um espaço-tempo de "lembrança de algo em suspenso", diante do qual experimentamos o enfrentamento com um outro tempo marcado pela confluência entre os elementos da história pessoal e da história coletiva. Esse "tempo-agora da lembrança" no teatro responde às mais diversas pulsões. Por vezes, pode surgir como ativação do espírito épico da lembrança, fazendo revolver, de forma obsessiva - como no teatro lírico-cerimonial de Kantor - as recordações da infância misturadas com reminiscências da história, assim como com os mais diversificados temas religiosos. Por outras, esse espaço-tempo da memória pode gerar, dentro da cultura avançada, uma espécie de "frágil banco de memória de imagens" (Fuchs 1996: 107) que retém cenas extraídas de narrativas conhecidas, ou reconstituiveis pelo espectador, assim como ocorre, por exemplo, em boa parte dos trabalhos de Robert Wilson, nos quais surge uma história universal como "caleidoscópio multicultural, etnológico, arqueológico"(Lehmann 2007: 131). No meio das paisagens de Wilson, que misturam tempos, culturas e espaços, costumam transitar figuras e temas universais colhidos a partir dos mais díspares contextos históricos, religiosos e literários: Einstein, Freud, Edison, a rainha Vitória, Rei Lear, São Sebastião, Tarzan, a Arca de Noé, o livro de Jonas, textos indianos, a Atlântida, Stonehenge ${ }^{1}$. Outras vezes, ainda, como na cena total de Robert Lepage - a que queremos aqui destacar, inicialmente essa dimensão temporal da memória suspensa surge a partir da transformação lúdica dos eventos, mobilizada pela distorção das lentes imperfeitas da memória, de modo a fazer com que a "história seja transformada em mitologia" (Lepage apud Dundjerovic 2007: 11). Daí a valorização, por parte de Lepage, do décalage do olhar estrangeiro, assim como o desprendimento em relação à
História oficial; nos Sete afluentes do rio Ota, sete personagens ocidentais de diferentes partes do mundo se interligam numa mesma estória que trata de questões ligadas a Hiroshima: "Senti que devíamos falar de Hiroshima como ocidentais e não ter a pretensão que iriamos contar o horror ou a beleza de Hiroshima como se fôssemos japoneses, isso seria completamente falso e desonesto" (Lepage 1999: 323).

De acordo com Hébert e Perelli-Contos (1998), o teatro de Robert Lepage insere-se numa linhagem da produção contemporânea que, partindo de um certo modo de apreensão do mundo fundado no diálogo permanente da memória e da imaginação, da ficção e da realidade, faz da cena um lugar de expressão visual do pensamento. Por meio desse tipo de teatralidade, a cena se transforma num espaço de manipulação que agencia outras visões de mundo por meio dos décalages que promove, permitindo ao criador (ator e espectador) arriscarse em livres associações de ideias, noções, elementos, mesmo quando eles parecem contraditórios e inconcebiveis se considerados do ponto de vista da representação linear. Isso porque, ao se apoiar, prioritariamente, na visualidade da cena, essa modalidade teatral permite aceder a um mundo invisivel onde as palavras não têm curso, perdendo sua afinidade com as ideias preestabelecidas que supostamente dominam o mundo - nenhuma verdade é considerada previamente à escritura cênica.

Esse processo de transformação lúdica da memória em que a cena deixa de ser uma "representação" do virtual e passa a ser a "repetição diferencial" dessa virtualidade - transmutação ímpar de um começo -, parece tratar a História como coisa "viva", promovendo a abordagem dos fatos a partir de novos ângulos. Além disso, cabe ressaltar, esta atualização de lembranças não se estabelece nunca de modo intencional, ocorrendo, antes, a partir da interseção entre as necessidades da situação presente e a estrutura virtual do passado; e mesmo quando, de forma 

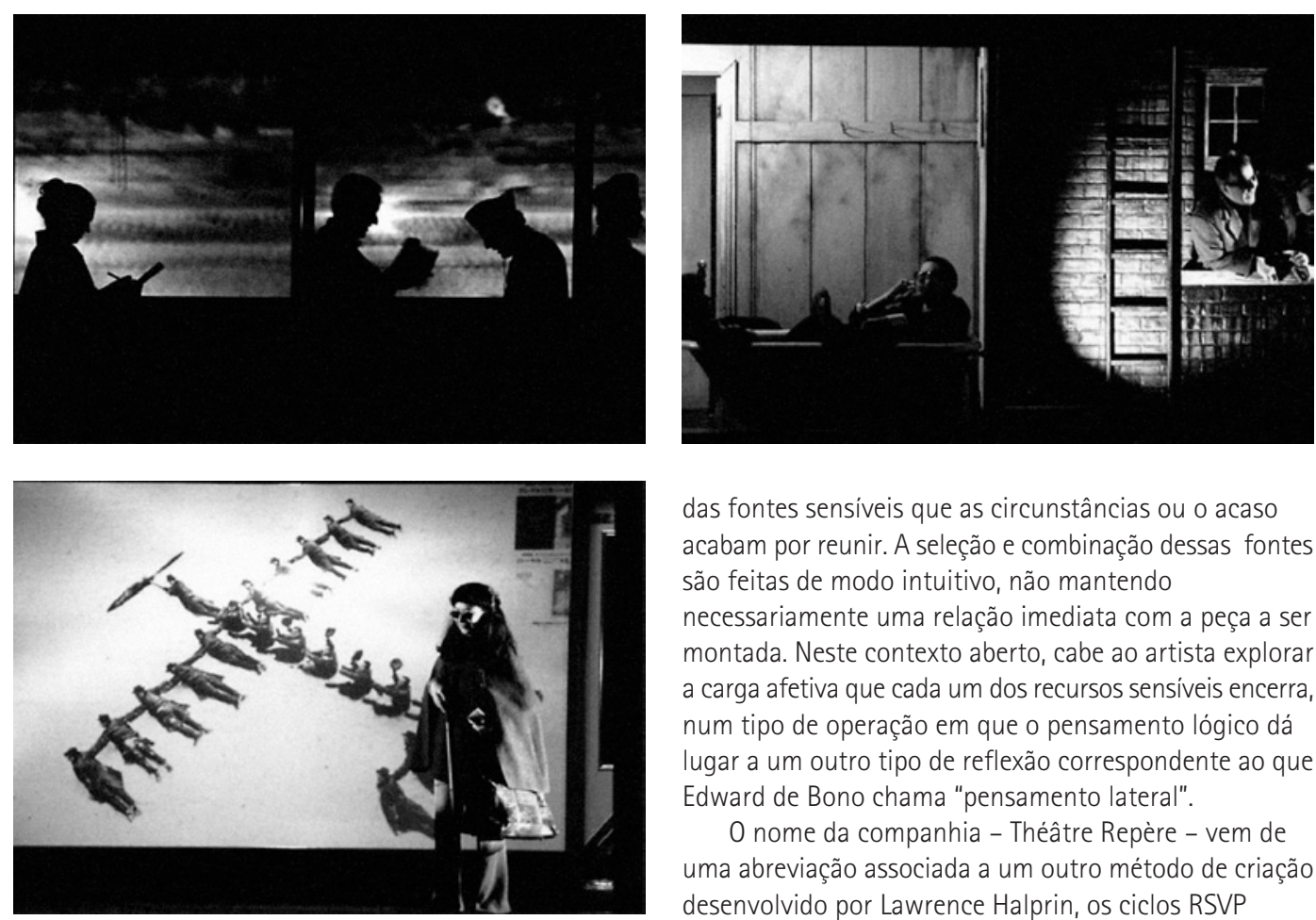

consciente, se convoca a memória, não se tem o controle sobre o modo como os vários elementos se atualizam. Essa irrupção de dados não intencionais, assim como a falta de controle sobre o processo de seriação do virtual, ao colocar sob suspeição o sentido prévio da escritura cênica e as intencionalidades do autor, promovem uma ruptura, radical, com a estruturação logo-fono-falocêntrica daquilo que, de acordo com Derrida, seria o palco teológico; o que, por sua vez, vem a refletir, de forma decisiva, aspectos da própria "metodologia" de criação de Lepage.

\section{Entre o método e a utopia}

Em seu artigo "Os processos de criação: entre o método e a utopia" (2005), Josette Féral afirma que, quando se juntou ao Théâtre Repère - companhia então dirigida por Jacques Lessard - no ano de 1982, Robert Lepage entrou em contato pela primeira vez com os chamados ciclos Repère, uma metodologia de criação que visa adotar fontes sensíveis - e não ideias - como pontos de partida para os processos, de modo a ativar e elaborar a linguagem criativa. Nesses processos os objetivos visados, as opiniões sobre o que se deve ou não realizar em cena, os sentidos e interpretações pré-determinados deixam de ter maior relevância. 0 processo se instaura por meio de uma "escuta" das fontes sensiveis que as circunstâncias ou o acaso acabam por reunir. A seleção e combinação dessas fontes são feitas de modo intuitivo, não mantendo necessariamente uma relação imediata com a peça a ser montada. Neste contexto aberto, cabe ao artista explorar a carga afetiva que cada um dos recursos sensiveis encerra, num tipo de operação em que o pensamento lógico dá lugar a um outro tipo de reflexão correspondente ao que Edward de Bono chama "pensamento lateral".

0 nome da companhia - Théâtre Repère - vem de uma abreviação associada a um outro método de criação desenvolvido por Lawrence Halprin, os ciclos RSVP (Resource, Score, Valuation, Performance), traduzidos para o francês por REPĖRE (Ressource, Partition, Évaluation, Représentation). Conforme nos lembra Féral, o método de Halprin consiste numa estratégia de criação desenvolvida por ele no campo da arquitetura, mas aplicável também em outros domínios, principalmente no campo da dança. Halprin desejava descrever o processo de trabalho do artista de maneira a evitar as explicações que se pautam única e exclusivamente por noções tais como inspiração e associação de ideias. Um segundo objetivo era tornar este processo, de certa forma, visivel, ou seja, encontrar um modo de transcrição simbólica que permitisse configurar concretamente a partitura da obra, o que poderia ser feito por meio de transcrições na forma de desenhos, croquis, sistemas de codificação, etc. Por fim, Halprin queria também elaborar um método de trabalho não-sistemático que pudesse responder às necessidades de artistas inseridos em processos de criação que estão em constante mobilidade. Logo, tal método, além do caráter flexivel, deveria ser orientado para o processo process oriented -, e não para o resultado.

De acordo com as conceituações de Halprin, a primeira etapa do ciclo RSVP - Resource - reúne tudo aquilo que serve de ponto de partida para a criação, compreendendo as fontes físicas e materiais, assim como as motivações

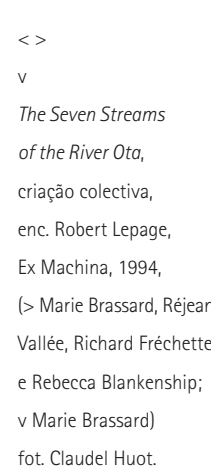

fot. Claudel Huot.

De acordo com Costa (2003), a apreensão da forma de narratividade própria a uma

determinada parcela da produção teatral

contemporânea torna-se, de certa maneira, problemática à medida que a posição do narrador ou foco narrativo não determina um lugar $e$ tampouco uma atualidade temporal mais ou menos seguros. Por esse viés, tanto o texto quanto sua encenação acabam por mobilizar apenas um jogo de hipóteses prováveis, uma vez que a fábula, o significado prévio e a intencionalidade do autor passam a estar sob suspeita. 
referentes às escolhas. A seleção dos recursos se dá de modo intuitivo e deve considerar a carga afetiva que cada um deles encerra. A segunda etapa, intitulada Score, está relacionada a uma fase de exploração das diversas "fontes" outrora levantadas, no sentido de lhes dar forma e orientação no espaço. É por meio dela que se começa a configurar uma "partitura" que, não sendo estática e envolvendo, muitas vezes, elementos irracionais, pode estar relacionada a diversos fatores: temporais, espaciais, musicais e/ou gestuais. Já na fase seguinte, Valuation, as proposições cénicas, elaboradas até então, são analisadas e/ou selecionadas, com o propósito de, a partir dos elementos propostos, deliberar ou não por determinada ação. 0 procedimento não é necessariamente racional e 0 acaso pode, por vezes, ter um papel importante. Por fim a última etapa do processo, Performance, está relacionada a uma fase onde se permite testar a eficácia, por exemplo, de uma fonte e de uma partitura, podendo ser instaurada em diferentes momentos. Isso porque não há um ordenamento preciso que antecipe o funcionamento das coisas no processo em sua estrutura cíclica. 0 andamento de um ponto a outro é múltiplo, podendo o círculo funcionar em qualquer sentido a partir de eixos transversais, de modo a permitir que cada parte entre em comunicação com as demais. Só as circunstâncias do momento, o desejo, a conveniência explicam a entrada por um ponto ou outro (Féral 2005: 154-164).

Esta classificação do ciclo por fases não tem como objetivo categorizar as etapas do processo de forma rígida, antes visa tornar o processo visivel de modo a permitir ao artista melhor se situar dentro do trabalho. Halprin compreende que o modelo que ele buscava deveria dar conta de dois fatores: de um lado, aspectos tais como o desejo, a vontade e os valores humanos. Do outro, a necessidade de decisão e escolha. Para Féral, uma certa visão do mundo está em causa em tal procura: uma visão que afirma o processo criador e a vontade de manter a obra em constante movimento, num continuo work in progress. Apesar de o trabalho necessitar da eliminação de certas opções experimentais ao longo do processo investigativo, evita-se todo tipo de julgamento de valor. Contudo, contrariamente ao que se poderia imaginar, não se trata, de modo algum, da instauração de uma ideologia coletivista, mas de permitir que a obra encontre sua forma a partir do trabalho de todos os envolvidos. A decisão final, no entanto, cabe ao encenador. A obra, nesse sentido, emerge como um ecossistema em transformação permanente.

Esse método visa oferecer outras vias de criação possiveis. Ou seja, ele desloca o artista de uma postura superior na qual ele se posiciona como conhecedor de sua arte, para o colocar numa relação direta consigo mesmo e com tudo que o cerca. Féral reconhece nessa metodologia - e também no View Points de Bogart reflexos do mencionado "pensamento lateral", uma forma de pensamento que privilegia o ato da criação e que se opõe ao "pensamento vertical" em seu modo de funcionamento. Nossa sociedade privilegia o pensamento vertical, ou seja, o pensamento estruturado racional e logicamente, no qual as situações são descodificadas em termos de probabilidades máximas. Enquanto o pensamento vertical se apoia na lógica, o pensamento lateral tende a abordar os problemas a partir de novos ângulos, revelando novos pontos de vista sobre as coisas.

Com os ciclos Repère, encontramo-nos, desse modo, frente a uma maneira de composição em que a obra deixa de ser produção e passa a ser o testemunho de um pensamento. E, em meio a este processo de espacialização do pensamento, as fronteiras entre interioridade e exterioridade, sujeito e objeto, mental e material são obliteradas. A ação de pensar sobre o próprio pensamento deixa de ser um domínio exclusivo da linguagem ou dos processos exclusivamente mentais e se investe do espaço em sua materialidade. Logo, os sujeitos passam a pensar com e por meio dos objetos, numa relação que rompe com a ideia que associa os primeiros aos agentes, e os segundos aos pacientes.

Conforme Bruno (2002), os termos quase-sujeitos e quase-objetos poderiam, ambos, designar tanto os homens quanto os artefatos técnicos, uma vez que os primeiros não são prioritariamente sujeitos, desde que também possuam artefatos técnicos. E estes últimos, por sua vez, não se limitam à condição de objetos, posto que não são simplesmente passivos e submissos à ação e à inteligência humana, pelo contrário, agem sobre as mesmas, engendrando deslocamentos e transformações que os elevam à categoria de quase-sujeitos. No caso de Lepage essa desfronteirização entre o sujeito e o objeto parece se refletir, principalmente, pelo fato de que a cena passa a "ditar" a sua própria história, assumindo, aos poucos, os contornos de uma certa perspectivação que mobiliza ações dramáticas; todavia, como nos lembra Ramos a partir de parâmetros puramente cênicos:

Outros, como Robert Lepage, propõem reatamentos em novos termos, com composições dramáticas não necessariamente mediadas pela literatura, mas articuladas já como cenas narrativas, numa poiesis em que mythose opsis se reconciliam. É nesta direção que parecem caminhar, no Brasil, a maioria dos grupos experimentais em seus processos hegemonicamente colaborativos. A cena passa a narrar 

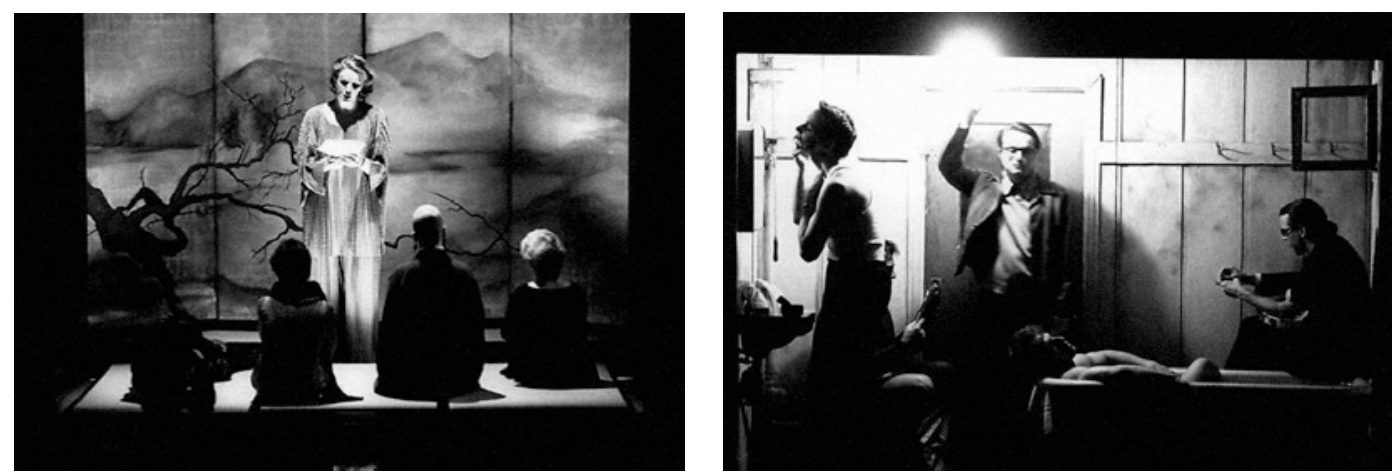

histórias por si, e a dramaturgia da cena torna-se um modo de operar a construção dramática em novos parâmetros: mais distanciados da literatura, mas, ainda, presos, essencialmente, à ideia de uma trama consequente de ações. A alternativa radical e o desafio continuam sendo pensar o espetáculo como puro opsis [...] (Ramos 2009: 98).

Após o sublime: "imaginação morta imagina" É muito dificil fazer uma imagem pura - declara Deleuze em "O esgotado", ao se referir ao tipo de imagem mobilizada pelas obras de Beckett associadas ao que o filósofo denomina por Lingua III. Uma imagem que, em toda a sua imparidade, não seja mais que uma imagem, ainda que o seu conteúdo seja bastante mediocre, bastante pobre, pois a força da imagem não se define pelo aspecto sublime do seu conteúdo, mas, antes, por sua "tensão interna". Ou, ainda, pela força que ela aciona, seja por se sustentar no vazio - imagem imóvel -, seja por estremecer no aberto - imagem trêmula -, como um pequeno ritornelo visual e sonoro. De acordo com o filósofo, é extremamente raro alcançar o ponto em que a imagem - destituída de toda marca de pessoalidade, racionalidade e intencionalidade - surge sem máculas de ordem representacional, alógica, quase afásica, de modo a afrouxar o torniquete das palavras, secar a ressudação das vozes, instaurando um espaço-tempo combustão, em meio ao qual a imagem pura espacializa o testemunho de um sujeito amnésico e reificado, ou seja, já, completamente, objetivado.

Ainda segundo Deleuze, não são poucos os que proclamam a obra integral e a morte do eu, porém, quando não se mostra, de fato, como esse eu se decompõe - o que inclui o erro, o mau cheiro e a agonia - tudo acaba em mera e inócua abstração. Do ponto de vista do filósofo francês, Beckett ultrapassa esse problema, ao promover, de maneira rigorosa, a mais extrema dissolução, decomposição do eu, por meio da troca indefinida de formulações matemáticas - combinatória - e da procura do informe e do "informulado", substituindo os projetos por tabelas e programas isentos de sentido.

Nestes termos, o grande contributo de Beckettà lógica, segundo Deleuze, consiste no fato de ele relacionar a ideia de esgotamento àquele modo de esgotamento de ordem mais propriamente fisiológica. Se a combinatória - a arte ou a ciência de esgotar o possivel através de disjunções inclusas - esgota seu objeto, é porque seu sujeito já se encontra esgotado: "Seria preciso estar esgotado para se dedicar à combinatória, ou então é a combinatória que juntos, a combinatória e o esgotamento?" (Deleuze 2010: 71-72); e o que conta para o esgotado já não é mais o "sentido" veiculado, mas sim, em qual ordem, e sob quais combinações, algo pode ser operado, uma vez que só ele é suficientemente desinteressado e escrupuloso a ponto de fazer algo sem qualquer função, justificativa ou finalidade; simplesmente, por fazer, até quando tiver necessidade. amnésico, afirma Deleuze, substitui a anamnese pelo esquecimento, a interpretação pela experimentação. Nesse sentido ele diz respeito não a toda a obra de Beckett, mas somente àquela parte relacionada ao que o filósofo francês designa como Lingua III (e que inclui, de forma enfática, os trabalhos televisivos). Diferentemente do que ocorre na Língua I (maculada pela razão), e na Língua II (maculada morta imagina", no qual já não se remete mais a linguagem a qualquer voz emissora - interromper as vozes, para se desprender da memória e da razão -, quando muito há uma voz monótona que descreve todos os elementos da imagem por vir, mas à qual falta uma forma. Tampouco há a retenção de qualquer coisa pessoal. É a língua não mais dos nomes, das vozes e das palavras, mas, antes, das imagens puras, sonantes e colorantes.

Cabe ressaltar que, em seus trabalhos televisivos, Beckett esgota por duas vezes o espaço e a imagem, à nos esgota, que nos leva ao esgotamento, ou os dois

0 esgotamento concerne apenas o testemunho pela memória), na Língua III atinge-se o ponto "imaginação
$<>$ The Seven Streams of the River Ota, criação colectiva, enc. Robert Lepage, Ex Machina, 1994 (> Michel Côté, Norman Daneau, Patrick Goyette e Réjean Vallée), fot. Claudel Huot. 

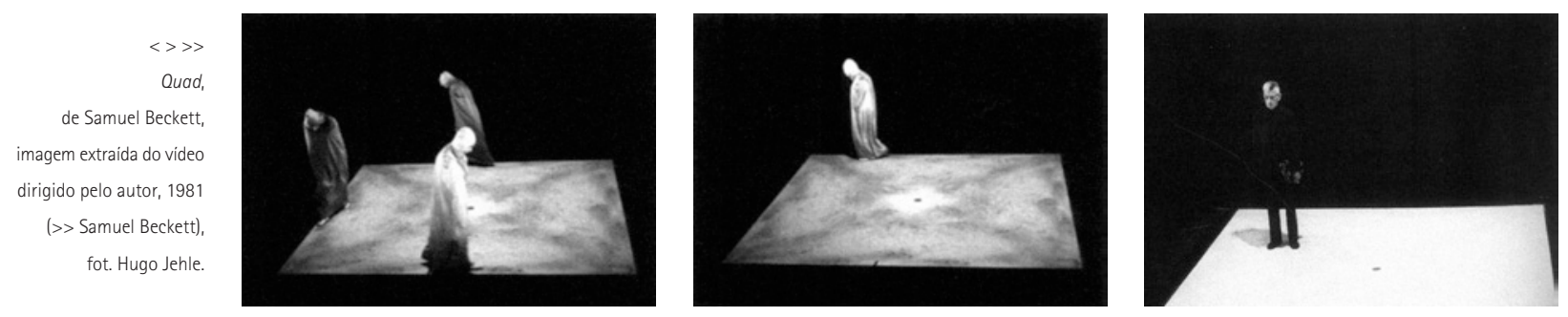

medida que as palavras Ihe pareciam, à altura, cada vez menos suportáveis em função da sobrecarga de cálculos, intenções, lembranças pessoais, histórias e hábitos que as cimentam. Segundo Deleuze, é a partir da obra televisiva que Beckett, superando as limitações impostas pelas palavras, atinge a mais extrema e radical anti-teatralidade, de modo que o gesto beckettiano ali passa a amputar de vez os últimos sinais da representação, ainda presentes em muitas das obras anteriores (nenhuma voz emissora, nenhuma memória, nenhuma razão, nenhum sentido, nenhum espírito). Neste ponto, podemos acrescentar, a lembrança de algo em suspenso (ou de algo sob suspeição) dá lugar à própria suspensão da lembrança; o que ocorre não como indice de um certo conforto, escapismo ou "alienação", mas, antes, como reflexo de um real estado de esgotamento.

De acordo com Lyotard (1997), o dado paradoxal relacionado à arte "após o sublime" é que esta se volta para algo que não diz respeito ao espírito; não é dirigida, tampouco se dirige ao espirito enquanto instância cuja destinação é questionar, relacionar alguma coisa e outra. A matéria (e sua imaterialidade), assim alegada, não preenche uma forma, de modo a atualizá-la; existe, insiste, de forma independente do espirito, longe da sua influência, fora de questão, livre de resposta, sem finalidade ou destinação. Uma vez que, após o sublime, encontramonos após o querer: "[s]ob o nome de matéria eu entendo a Coisa. A Coisa não espera ser destinada a algo" (Lyotard 1997: 145-146).

\section{Referências bibliográficas}

BELLONI, Arthur E. A. (2011), Teatro menos teatro, São Paulo, ECA/USP. (Tese de Doutoramento).

BRUNO, Fernanda (2002), "Tecnologias cognitivas e espaços do pensamento", in Livro da XI Compós, Porto Alegre, Editora Sulina.

COSTA, José da (2003), Teatro brasileiro contemporâneo, Rio de Janeiro, Universidade do Estado do Rio de Janeiro. (Tese de Doutoramento). COLWELL, Chauncey P. (1997), "Deleuze \& Foucault: Series, Event, Genealogy", in Theory \& Event, Volume 1, Issue 2, The John Hopkins University Press.
DELEUZE, Gilles (2010), "O esgotado", in Sobre o teatro, trad. Ovidio de Abreu e Roberto Machado, Rio de Janeiro, Jorge Zahar Editor Ltda. DUNDJEROVIC, Aleksandar (2007), The Theatricality of Robert Lepage, texto policopiado.

FÉRAL, Josette (2005), "Les processus de création: entre méthode et utopie", in Mises en Scène du Monde. Colloque Internacional de Rennes, Paris, Les Solitaires Intempestifs, pp. 154-166.

-- (2008), "Por uma poética da performatividade: o teatro performativo", in Sala Preta, São Paulo, ECA/USP, Volume 8, pp.197-210.

FUCHS, Elinor (1996), The death of Character: Perspectives on Theater after Modernism, Indianapolis, Indiana University Press.

HÉBERT, Chantal / PERELLI-CONTOS, Irène (1998), "L'écran de la pensée ou les écrans dans le théâtre de Robert Lepage", in Béatrice PiconVallin (org.), Les écrans sur la scène, Lausanne, L'Âge d'homme, pp. 171-206

KOBIALKA, Michal (2005), "Kantor está morto! Esqueçam Kantor!", in Sala Preta, São Paulo, ECA/USP, Volume 5, pp.225-232

LEHMANN, Hans-Thies (2007), Teatro pós-dramático, trad. Pedro Sussekind, São Paulo, Cosac Naify.

-- (2009), "Até que ponto o teatro pós-dramático é politico?", in HansThies Lehmann, Escritura politica no texto teatral, trad. Priscila Nascimento, São Paulo, Perspectiva, pp.1-14

LEPAGE, Robert (1999), "Robert Lepage", in Maria M. Delgado / Paul Heritage, Diálogos no palco: 26 diretores falam de teatro, Rio de Janeiro, Livraria Francisco Alves Editora S.A.

LYOTARD, Jean-François (1997), "The Tooth, the Palm", in Timothy Murray, Mimesis, Masochism \& Mime, the Politics of Theatricality on Contemporary French Thought, Ann Arbor, The University of Michigan Press, pp. 282-288.

-- $O$ inumano (1997), trad. Ana Cristina Seabra e Elisabete Alexandre, Lisboa, Editorial Estampa.

PAVIS, Patrice (2010), A encenação contemporânea, trad. Nanci Fernandes, São Paulo, Perspectiva.

PUCHNER, Martin (2002), Stage Fright: Modernism, Anti-theatricality \& Drama, Baltimore \& London, The John Hopkins University Press. RAMOS, Luiz Fernando (2009), "Por uma teoria contemporânea do espetáculo: mimesis e desempenho espetacular", in Texto e imagem: Estudos de teatro, Rio de Janeiro, 7Letras, pp. 89-103. 